\title{
Design of Teaching Board for Principle of Pulse Width Speed Control System
}

\author{
Hejia Li ${ }^{1, a^{*}}$, Rui Zhu ${ }^{1, b}$, Hongri Wang ${ }^{1, c}$,Zhiping Zhang ${ }^{1, d}$, \\ Donghua Zhuang ${ }^{1, e}$, Yue Zhao ${ }^{1}$ and Ou Qi ${ }^{1, f}$ \\ ${ }^{1}$ No.1, Huayuan Road, Changchun City, Jilin Prov. China 130117 \\ a275039646@qq.com, b78078798@qq.com, ${ }^{\text {c862851960@qq.com, }{ }^{\text {d}} 409956377 @ q q . c o m, ~}$ \\ e365384062@qq.com, ${ }^{\mathrm{f}} 249214312 @ q q . c o m$
}

Keywords: Pulse width modulation; Teaching board; Gun control system; Horizontal control

\begin{abstract}
Along with our country economic strength unceasing enhancement, our army also ushered in the weaponry modernization high speed development time, a batch of new type weaponry one after another equips our army armored mechanization troop, the weaponry unceasing development, the high-tech introduction has brought the tremendous enhancement to the troop combat strength, but the subsequent equipment failure Maintenance support is much more difficult than before. The horizontal gun control system of the new tank adopts PWM (pulse width speed control system), which has more advantages than the polarization relay control technology used in the past. PWM is integrated into the output board of the control box, the circuit board is small, and it is difficult to understand the control flow visually. Therefore, a teaching board of pulse width speed control system principle is researched and made. Most of the components in the teaching board are in-vehicle physical objects. The circuit connection is completely in accordance with the design of the real vehicle, and a variety of display modules and analog fault points are added, which can make the learners more intuitive understanding of the pulse width speed control system principle and fault points. Master the methods to solve the common faults of the control box, at the same time, in the process of making the teaching board, we also have a deeper understanding of the principle of horizontal control of the gun control system, improve the learners and maintenance personnel ability to remove the complex faults of the horizontal control system of the gun control system, and enhance the practical operation ability.
\end{abstract}

\section{Introduction}

Along with our country economic strength unceasing enhancement, our army also ushered in the weaponry modernization high speed development time, a batch of new type weaponry one after another equips our army armored mechanization troop, the weaponry unceasing development, the high-tech introduction has brought the tremendous enhancement to the troop combat strength, but the subsequent equipment failure Maintenance support is much more difficult than before.

The new armored gun control systems all adopt the pulse width control system, which has more advantages than the polarization relay control technology used in the past. Therefore, the principle of the pulse width control system is not only the focus of teaching, but also the difficulty. The learners need to study the control principle repeatedly if they want to master it deeply. Because of the complexity of control theory, learners have great obstacles in learning and reviewing[1] .

\section{Research Background}

PWM is a motor control technology widely used in our new armored equipment, and it is also the development direction of new all-electric armored equipment in the future[2]. The principle of pulse width speed control system is more complex and difficult to understand. It is more difficult for maintenance personnel to master this technology. In order to facilitate and improve teaching efficiency, this teaching board is researched and made. 


\section{Purpose and Significance of Research}

Pulse width control technology is widely used in military and civilian equipment control systems for its precise performance. Nowadays, the new type tank and armored vehicles equipped with the army generally adopt this technology to realize motor speed regulation and temperature control. The new tank fire control system is to use this technology to realize the control of the aiming speed and the temperature of the full liquid floating rate gyroscope of the horizontal gun control system.

But PWM control technology is high, the signal is diverse, the working principle is complex, in the training process, the maintenance personnel is difficult to achieve a deep understanding with the intuitive impression, the maintenance ability is weak. Therefore, the new tank horizontal gun control system work process as a traction, using signal flow, signal numerical value, signal waveform real-time display technology, the integration of equipment work and principle knowledge in the form of a teaching board system display, improve the maintenance staff's cognitive level and maintenance ability. Through the design and manufacture of the teaching board of the principle of pulse width control, the learners will master the process of selecting the subject, designing the scheme, collecting the data, making, testing, and finishing the questions. At the same time, the practical and innovative abilities will be further improved.

\section{Principle Analysis}

Pulse width modulation control system is a pulse width modulation of high-frequency switch control mode, the formation of pulse width modulation converter - motor speed control system, referred to as PWM pulse width control system

By changing the ratio of switching on time (ton) and switching period (T) of the high power transistor, the duty cycle of the pulse is changed, and the average voltage at both ends of the motor changes accordingly, so the speed of the motor is controlled.

The control structure of the driving device can be divided into two parts. The circuit that transfers energy from the main power supply to the motor is called the power conversion circuit, and the rest is called the control circuit.

The DC voltage Us required by the DC motor is applied to a bridge (H-type) power conversion circuit consisting of four high-power transistors (GTR) V1, V2, V3 and V4. The high-power transistor provides the rectangular wave base excitation voltage with a phase difference of 180 degrees to V1, V4, V2 and V3 by the control circuit, and the V1, V4 and V2, V3 are alternately turned on. It can also be other conduction mode, as long as it does not constitute a DC short circuit of the opposite tube on the same side, the DC voltage Ui is modulated into a square wave pulse voltage with the same frequency, which acts on both ends of the armature of the motor to provide energy for the motor.

The control circuit is usually composed of constant frequency waveform generator, pulse width modulation circuit, pulse distribution circuit, base drive circuit, protection circuit and other basic circuits.

PWM driving device has the following characteristics compared with the general thyristor drive device:the high-power controllable devices needed are few, the circuit is simple, the speed range is wide, the speed is good, the current waveform system is good, the additional loss is small, and the power factor is high, which is beneficial to users.

In the new tank of our army, the horizontal gun control system adopts the PWM pulse width speed control system. The control system is integrated into the output board of the control box, so as to control the speed of the horizontal turret motor and achieve the desired control effect.

The control box output board circuit is composed of control signal processing circuit, triangle wave generating circuit, comparator circuit, switch circuit, overvoltage protection circuit and so on.

\section{Detection Principle Analysis of Pulse Width Speed Control System}

The teaching board mainly detects the input and output signals of the pulse width control system, 
mainly the voltage signal. The detected signal is divided into DC voltage signal and pulse signal. The DC voltage signal is detected and displayed by voltmeter. The pulse signal is detected and displayed by oscilloscope. The main DC voltage signals include input main control signal, two signals processed by control signal, two voltage signals of switching circuit and voltage feedback signal. The main pulse signals include triangle wave signal and comparator circuit pulse signal.

\section{Circuit Design}

In order to be more close to the actual equipment effect, so Basic circuit design of teaching board for principle of pulse width speed control system ses the vehicle motor amplifier control box output board as the basic template, the original parts are used in the real vehicle original model.

Detection circuit design. Pulse Width Speed Control System Principle Teaching Board uses six voltmeters and three oscilloscopes to display the real-time voltage and output pulse voltage waveform of the pulse width speed control system. Six voltmeters are connected to the main control signal input terminal, inverter N18, N20 output terminal, feedback signal input terminal, transistor V4, V5 collector terminal according to the required real-time voltage. The 3 oscilloscope is connected to the triangular wave output terminal, and the comparator N23 compares the output side of the voltage square wave signal.

Fault circuit design. According to the principle of pulse width speed control system, the teaching board needs to realize the fault phenomenon, in the appropriate position in the circuit to set the break fault point, using relays to achieve. The first fault point is set at the input of the main control signal, the second fault point is set at the output of the comparator and controlled by a double-pole relay, the third fault point is set at the input of the driving voltage, and the fourth fault point is set at the input of the feedback signal.

Circuit making. Protel $99 \mathrm{SE}$ is Protel's latest Windows-based sixth-generation product in 2000[7] . It has powerful automatic design capability, high-speed and effective editing function, simple and convenient design process management PDM. It can complete the whole process of electronic products from electrical conceptual design to physical production data generation. This intermediate analysis, simulation and verification.

Its main functional modules include circuit schematic design, PCB design, no network wiring device, programmable logic device design, circuit diagram simulation/simulation, etc. It integrates the circuit design and development environment.

\section{PLC Programming}

Pulse Width Speed Control System Principle Teaching Board not only provides the display of voltage and waveform changes when the pulse width speed control system works, but also has certain teaching function. In order to realize the horizontal principle teaching of the teaching board, the teaching board panel uses LED lights to display the signal flow direction under various working conditions, which is convenient for teachers to teach. In order to realize the sequential display of LED, the teaching board uses Siemens PLC programmable logic controller to realize the lighting sequence function of panel LED lights.

The SIEMENS S7-200 series is a programmable logic controller. It can control various devices to meet the needs of automation control[8] [9]. This teaching board PLC model adopts SIEMENS S7-200 CPU224XP and IO module. The main voltage is given at the same time access circuit board and PLC analog channel. The relay adopts DC24V small electromagnetic relay. The semi-automatic aiming program is shown in Fig.1. 


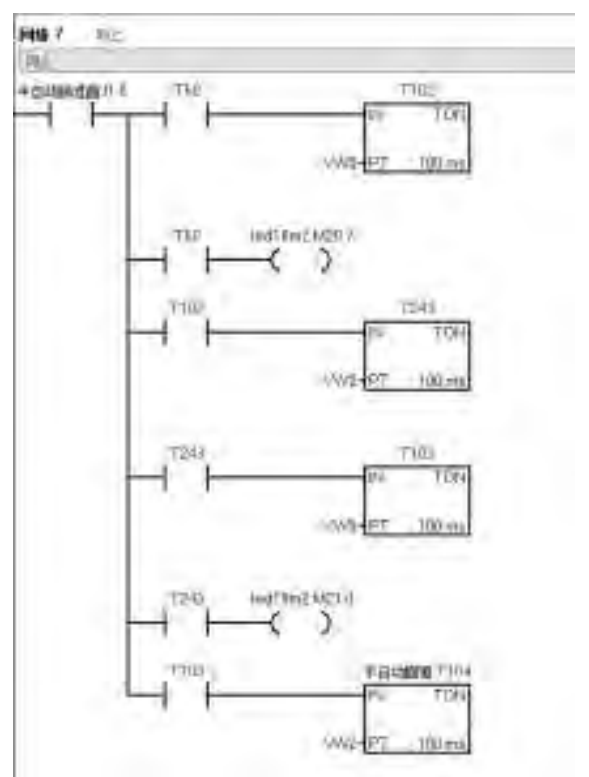

\begin{tabular}{|l|l|l}
\hline 符号 & 地址 & 注释 \\
\hline led18m2 & M20.7 & \\
\hline led19m2 & M21.0 & \\
\hline 半自动瞄准按钮 & 11.0 & \\
\hline 半自动瞄准走到子... & $\mathrm{T} 104$ & \\
\hline
\end{tabular}

Figure 1. The semi-automatic aiming program

\section{Installation and Debugging}

The teaching board adopts DC stabilized power supply, oscilloscope, LED, PLC module, PLC expansion module and other components.

After installation, the whole debugging work of the teaching board is started. According to the function of the teaching board design, the actual effect of each working condition and failure of the teaching board is perfected, and the expected production effect is achieved.

\section{References}

[1] Huijing piao tank fire control system construction principle and repair. Beijing: National Defense Industry Press

[2] Yiying Gang Construction principle and repair of infantry combat vehicle fire control system. Armored Force Technical College.

[3] Jiping Yang Visio 2007 graphic design from novice to master. Beijing: Tsinghua University press,2008.e.

[4] Feng Li Analog Electronic Technology Foundation (Fourth Edition). Beijing: China University of Mining and Technology press, 2007.

[5] Shi Yan Digital Electronic Technology Foundation (Fifth Edition). Beijing: Higher Education Press, 2008.

[6] Rong Yi-Yu electrical and electronic technology. Beijing: People's post and Telecommunications Publishing House, 2011.

[7] Nian Chun Yao Protel99SE basic course. Beijing: people post and Telecommunications Press, 2009.

[8] Jiangwen Zhao SIEMENS S7-200 PLC programming from entry to mastery. Beijing: China Electric Power Press,2013.

[9] SIMATIC S7-200 programmable logic controller system manual. 